\title{
BLEEDING TIME AND CLOTTING TIME IN DIFFERENT BLOOD GROUPS- A CROSS SECTIONAL STUDY
}

\author{
Laishram Leimahanbi Chanu1, Rajkumar Bikramjit Singh², Bishwalata Rajkumari³, Sumpi Rosemary Anal4
}

${ }_{1}^{1}$ Demonstrator, Department of Physiology, Jawaharlal Nehru Institute of Medical Sciences, Imphal, Manipur, India.

${ }^{2}$ Assistant Professor, Department of Medicine, Regional Institute of Medical Sciences, Imphal, Manipur, India.

${ }^{3}$ Associate Professor, Department of Community Medicine, Jawaharlal Nehru Institute of Medical Sciences, Imphal, Manipur, India.

${ }^{4}$ Assistant Professor, Department of Physiology, Jawaharlal Nehru Institute of Medical Sciences, Imphal, Manipur, India.

ABSTRACT
BACKGROUND
Blood group plays a vital role in the field of transfusion medicine, forensic pathology, and is genetically determined. Some authors
have found epistaxis to be more common in people with O blood group, while some other authors found no association. We assess ed
the effect of ABO blood group system on the bleeding time (BT) and clotting time (CT) of medical students.

\section{METHODS}

A total of 77 MBBS students consisting of 32 females and 45 males in the age group of 18-25 yrs. were selected. The exclusion criteria for selection of the students were any history of bleeding disorders and NSAID intake. Data was collected in cluding age, sex, height and weight. Blood grouping and estimation of bleeding time and clotting time was done for all subjects.

\section{RESULTS}

The mean age of the 77 students was $19.4 \pm 1.07$ years. There were more males $(58.41 \%)$ than females $(41.6 \%)$ in the study group. The most common blood group was 0 +ve (29.9\%) followed by B +ve (29.9\%), A +ve (27.3\%) and AB +ve (14.3\%). There was no Rh -ve blood group. The mean BT in seconds was $151 \pm 33$ (range 60 to 270). The mean CT was $224 \pm 49$ seconds (range 120 to 360 ). The BT and CT in all the subjects were found to be within normal range.

\section{CONCLUSIONS}

In the present study, $\mathrm{O}$ blood group was found to be the most common among the various blood groups in both males and females. Our study also shows a trend of longer BT in females and longer CT in females, but these were not statistically significant.

\section{KEY WORDS}

Hematology, Blood Disorder, ABO System, Medical Student

HOW TO CITE THIS ARTICLE: Chanu LL, Singh RB, Rajkumari B, et al. Bleeding time and clotting time in different blood groups- a cross sectional study. J. Evolution Med. Dent. Sci. 2019;8(22):1813-1815, DOI: 10.14260/jemds/2019/398

\section{BACKGROUND}

Scientist Karl Landsteiner first described the ABO blood group in 1900 and it served the beginning of blood banking and transfusion medicine.(1)Blood group plays a vital role in the field of transfusion medicine, forensic pathology, and is genetically determined. Blood group may also have some association with diseases like duodenal ulcer, diabetes mellitus, urinary tract infection and foeto-maternal incompatibility leading to haemolytic diseases of new born. ABO blood grouping is based on antigenic property of red blood cells. The gene for $\mathrm{ABO}$ group is present on chromosome 9 while for Rh system it is on chromosome 1 . The Rh system is one of the most polymorphic of the human blood groups. According to the presence or absence of $\mathrm{Rh}$ antigens blood is classified into Rh positive or negative. Type A individuals have the antigen $A$, type $B$ have antigen $B$, and type $A B$ have both; type $O$ have neither of these antigens. These $A$ and $B$ antigens are complex oligosaccharides presented on the surface of red blood cells that differ in their terminal sugar.(2)

'Financial or Other Competing Interest': None.

Submission 05-04-2019, Peer Review 09-05-2019,

Acceptance 15-05-2019, Published 03-06-2019.

Corresponding Author:

Sumpi Rosemary Anal,

C/o. Sumpi Residence,

$1^{\text {st }}$ Street New Lambulane,

Imphal-795005, Manipur, India.

E-mail: sumpirose@gmail.com

DOI: $10.14260 /$ jemds $/ 2019 / 398$
It has been reported that Caucasian population with Blood group $\mathrm{O}$ have higher admission rates in hospital for epistaxis compared with the general population.(1) Some authors have found that epistaxis is commonly seen in people with 0 blood group when compared with other ABO blood groups, and they also observed that there is a lower expression of von Willebrand factor (vWf) in them.(2) vWf is a blood glycoprotein involved in haemostasis, synthesized by endothelial cells and megakaryocytes. It helps in platelet adhesion and platelet aggregation. It also acts as a special carrier protein for the clotting factor VIII (Anti-haemophilic factor A). Therefore, the $\mathrm{ABO}$ blood group system may have influences in the bleeding time (BT) and clotting time (CT). Bleeding Time is the time interval between the skin puncture and spontaneous stoppage of bleeding. It is mainly a test to assess the platelet adhesion and aggregating and can be prolonged significantly in conditions with defective platelet functions, either congenital or acquired. The time interval between the blood vessels puncture and fibrin threads formation is the Clotting time. CT is prolonged in conditions in which clotting factors are defective or deficient. The normal values of Bleeding Time generally lie in the range of $1-5 \mathrm{~min}$. The normal Clotting Time ranges between 5-11 min. Nowadays, these tests are widely used not just for evaluation of platelet function but also to assess the effects of medications and medical devices (Such as cardiopulmonary bypass or dialysis machines) on homeostasis status. The most important advantage of BT test is its ability to evaluate normal body homeostasis and the role of vessels in this process. Thus, relationship between BT, CT, and blood groups is important in certain clinical settings. 


\begin{tabular}{|c|c|c|}
\hline Variable & Category & Frequency (\%) \\
\hline \multirow{4}{*}{ Age } & 17 & $4(4.5)$ \\
\cline { 2 - 3 } & 18 & $10(13)$ \\
\cline { 2 - 3 } & 19 & $22(28.6)$ \\
\cline { 2 - 3 } & 20 & $31(40.3)$ \\
\cline { 2 - 3 } & 21 & $9(11.7)$ \\
\hline \multirow{4}{*}{ Sex } & 22 & $1(1.3)$ \\
\cline { 2 - 3 } & Male & $45(58.4)$ \\
\hline \multirow{4}{*}{ Blood group } & Female & $32(41.6)$ \\
\cline { 2 - 3 } & $0+\mathrm{ve}$ & $23(29.9)$ \\
\cline { 2 - 3 } & $\mathrm{A}+\mathrm{ve}$ & $21(27.3)$ \\
\cline { 2 - 3 } & $\mathrm{B}+\mathrm{ve}$ & $11(14.3)$ \\
\hline \multirow{4}{*}{ Table 1. Background Characteristics of The Participants (n=77) } \\
\hline \multirow{2}{*}{ AB +ve }
\end{tabular}

\begin{tabular}{|c|c|c|c|}
\hline Variable & Mean \pm SD & Median & Range \\
\hline Age (years) & $19.44 \pm 1.07$ & 20 & $17-22$ \\
\hline Height (cm) & $164.04 \pm 9.1$ & 164 & $140-185$ \\
\hline Weight (kg) & $56 \pm 9.39$ & 55 & $40-82$ \\
\hline BT (sec) & $151.69 \pm 33.42$ & 150 & $60-270$ \\
\hline CT (sec) & $224.68 \pm 49.49$ & 210 & $120-360$ \\
\hline SBP (mmHg) & $118.77 \pm 7.37$ & 120 & $100-137$ \\
\hline DBP (mmHg) & $80.72 \pm 5.69$ & 80 & $70-100$ \\
\hline Pulse (beats/min) & $74.28 \pm 6.44$ & 72 & $60-94$ \\
\hline Table 2. Mean, Median and Range of Background Variables \\
\hline
\end{tabular}

\begin{tabular}{|c|c|c|c|c|}
\hline \multirow[b]{2}{*}{$\begin{array}{l}\text { Blood } \\
\text { Group }\end{array}$} & \multicolumn{3}{|c|}{ BT Percentile, N (\%) } & \multirow[b]{2}{*}{ p-Value } \\
\hline & $\begin{array}{c}<25^{\text {th }} \\
\text { Percentile }\end{array}$ & $\begin{array}{l}25^{\text {th }}-75^{\text {th }} \\
\text { Percentile }\end{array}$ & $\begin{array}{c}\geq 75^{\text {th }} \\
\text { Percentile }\end{array}$ & \\
\hline $\mathrm{O}+\mathrm{ve}$ & $2(8.7)$ & $15(65.2)$ & $6(26.1)$ & \multirow{4}{*}{0.513} \\
\hline A +ve & $0(0)$ & $12(57.1)$ & $9(42.9)$ & \\
\hline $\mathrm{B}+\mathrm{ve}$ & $1(4.5)$ & $17(77.3)$ & $4(18.2)$ & \\
\hline $\mathrm{AB}+\mathrm{ve}$ & $0(0)$ & $8(72.7)$ & $3(27.3)$ & \\
\hline
\end{tabular}

Table 3. Comparison of BT Percentile Cut-Off with Blood Groups $(n=77)$

\begin{tabular}{|c|c|c|c|c|}
\hline \multirow[b]{2}{*}{$\begin{array}{l}\text { Blood } \\
\text { Group }\end{array}$} & \multicolumn{3}{|c|}{ CT Percentile, N (\%) } & \multirow[b]{2}{*}{ p-Value } \\
\hline & $\begin{array}{c}<25^{\text {th }} \\
\text { Percentile }\end{array}$ & $\begin{array}{l}25^{\text {th }}-75^{\text {th }} \\
\text { Percentile }\end{array}$ & $\begin{array}{c}\geq 75^{\text {th }} \\
\text { Percentile }\end{array}$ & \\
\hline $0+$ ve & $2(8.7)$ & $14(60.9)$ & $7(30.4)$ & \multirow{4}{*}{0.298} \\
\hline$A+v e$ & $1(4.8)$ & $11(52.4)$ & $9(42.9)$ & \\
\hline $\mathrm{B}+\mathrm{ve}$ & $2(9.1)$ & $7(31.8)$ & $13(59.1)$ & \\
\hline $\mathrm{AB}+\mathrm{ve}$ & $0(0)$ & $8(72.7)$ & $3(27.3)$ & \\
\hline \multicolumn{5}{|c|}{$\begin{array}{l}\text { Table 4. Comparison of CT Percentile Cut-Off with Blood Groups } \\
(n=77)\end{array}$} \\
\hline
\end{tabular}

At the same time Daniel $\mathrm{M}$ et al in his study, could not find any association between $\mathrm{ABO}$ group and von Willebrand factor.(3) The objective of this study was to assess the relationship between bleeding time and clotting time among various Blood groups and also to identify any gender difference among the same.

\section{METHODS}

This cross-sectional study was carried out in the department of Physiology, Jawaharlal Nehru Institute of Medical Sciences, Imphal. A total of 77 1st year MBBS students consisting of 32 females and 45 males under the age group of 18-25 yrs. were selected. The exclusion criteria for selection of the students were any history of bleeding disorders and history of NSAID intake. Institutional ethical committee clearance was obtained. Data was collected in respect to the age, sex, height, weight etc. after obtaining informed consent.

Blood group determination was done by adding antisera $\mathrm{A}$ and $B$ with the blood sample and confirmation was done by the appearance of agglutination amongst RBCs under low power microscope. Estimation of bleeding time was done by Duke's method. A deep skin puncture was made, and the length of time required for bleeding to stop was recorded by blotting the drops of blood from the incision every 30 seconds using blotting paper until the bleeding stops. Clotting time was estimated by capillary tube method. In this method, a deep skin puncture was made using a lancet and the blood was filled into a capillary tube by capillary action.

Then after a lapse of 1 minute the capillary tube was broken about 3 to $4 \mathrm{~mm}$ from one end and thereafter every 30 seconds until the appearance of a thin fibrin thread. The clotting time was recorded at the point of appearance of the fibrin thread. The purpose and procedure of the study were explained to each student.

Statistical analysis was done using IBM SPSS version 20. Descriptive statistics like mean, percentages, percentiles etc., were calculated and Chi-square test was used to test for association. A p-value of $<0.05$ was taken as significant.

\section{RESULTS}

The mean age of the 77 students was $19.4 \pm 1.07$ years. There were more males (58.41\%) than females $(41.6 \%)$ in the study group. The most common blood group was $0+$ ve $(29.9 \%)$ followed by B +ve (28.6\%), A +ve (27.3\%) and AB +ve (14.3\%). There was no $\mathrm{Rh}$-ve blood group. The mean $\mathrm{BT}$ in seconds was $151 \pm 33$ (range 60 to 270). The mean CT was $224 \pm 49$ seconds (Range 120 to 360 ). The BT and CT in all the subjects were found to be within normal range.

Upon dividing the results of the BT into 3 groups as $<25^{\text {th }}$ percentile (Group 1), $25^{\text {th }}$ to $75^{\text {th }}$ percentile (Group 2) and $>$ $75^{\text {th }}$ percentile (Group 3), there was a trend for longer BT $\left(>75^{\text {th }}\right.$ percentile) in the A +ve group (49.2\%) as compared to $\mathrm{AB}+$ ve $(27.3 \%), 0+$ ve $(28.1 \%)$ or $\mathrm{B}+$ ve group $(18.2 \%)$ but this was not statistically significant $(\mathrm{p}=0.513)$. Similarly, more females $(31.2 \%)$ had longer BT ( $>75^{\text {th }}$ percentile) as compared to males $(26.7 \%)$ but the difference was not statistically significant $(\mathrm{p}=0.912)$.

Upon dividing the results of the CT into 3 groups as $<25^{\text {th }}$ percentile (Group 1), 25 th to $75^{\text {th }}$ percentile (Group 2) and $>$ $75^{\text {th }}$ percentile (group 3 ), there was a trend for longer CT $\left(>75^{\text {th }}\right.$ percentile) in the $\mathrm{B}+\mathrm{ve}$ group $(59.1 \%)$ as compared to $\mathrm{A}+\mathrm{ve}(42.9 \%), \mathrm{O}+\mathrm{ve}(30.4 \%)$ or $\mathrm{AB}+\mathrm{ve}$ group $(27.3 \%)$ but this was not statistically significant $(\mathrm{p}=0.298)$. More males (44.4\%) had longer CT (> 75 th Percentile) than females $(37.5 \%)$ but the difference was not statistically significant $(\mathrm{p}=0.671)$.

\section{DISCUSSION}

Haematological parameters are a very important diagnostic tool and are used as a routine clinical evaluation of health as well as an essential factor for surgeons and anaesthesiologist before initiating any surgical procedure. Hence, in hospitals blood tests are performed in routine. Evaluation of blood groups, bleeding time and clotting time are the most important and initial haematological parameters. In a study by $B$ Mahapatra et al(4) 0 group was found in more number of students (37.8\%) than A (21.9\%), B (34\%) and AB (6.3\%). In another study by Roy B et al,(1) O blood group was also the more prevalent group (35.2\%) than A (30.5\%), B (28.9\%) and $\mathrm{AB}(5.5 \%)$. Similar findings were observed in our study, with 0 group being the most common one at $29.9 \%$. Some other studies showed B blood group as the most common one. Aleem A et al found B blood group (35.2\%) more common than 0 (29.5\%), A (14.7\%) or AB (12.3\%). In our study BT was found 
to be more prolonged in A than other blood groups though this was not statistically significant. This was in contrast to the study performed by Mahapatra B et al where BT was more in B blood group. ${ }^{(4)}$ In another study by Baishya R et al, BT was most prolonged in 0 group.(5) Aleem $\mathrm{A}$ et al found Bleeding time to be greater than others in $\mathrm{AB}$ blood group in females and ' $O$ ' blood group in males but the values were not significantly different.(6)

CT was longer in B blood group in our study though these were also not statistically significant. This was in contrast to the study of Mahapatra B et al where CT was found to be more prolonged in $\mathrm{AB}$ group.(4) Baishya $\mathrm{R}$ et al found prolonged CT in $\mathrm{O}$ group.(5) Aleem $\mathrm{A}$ et al found significantly higher Clotting time in $\mathrm{O}$ blood group in females, and in B blood group and males. (6) Our study showed a trend for longer BT in females compared to males which is in accordance with the study performed by Roy B et al.(1) Aleem A et al found higher bleeding time as well as higher clotting time in females. (6) Adhana R et al studied correlation of blood groups, BT and CT in male and female students. (7) They conducted a study on 200 volunteers. 84 were males and 116 were females. They found that the mean BT and CT in males were 128.69 and 219.88 seconds respectively. The mean BT and CT were 133.28 and 223.97 seconds respectively. In females, significant mean BT $(p=0.047)$ were found as compared to males in this study. This finding was similar to that of our study where BT was found to be more prolonged in females than males though this was not statistically significant. Baishya $\mathrm{R}$ et al studied gender wise relation of BT and CT of 154 students, of which 59 were females and 95 were males.(5) They found that the BT and CT were higher in females as compared to males. This increased $\mathrm{BT}$ in females can be due to the effects of oestrogens, which reduces the function of platelets.(8) BT is reduced in males due to increased activation and aggregation of platelets.(9)

However, in another study done by Mahapatra B et al, there was no difference in the bleeding time and clotting time among the males and females. (4) A study with a bigger sample size may give a better picture.

Duke's method for BT and capillary tube method for CT, though easy and inexpensive, are not very accurate methods. Future studies can be conducted using more accurate method such as prothrombin time, activated partial thromboplastin time, study of platelet aggregation and determination of coagulation factors.

\section{CONCLUSIONS}

In the present study, $\mathrm{O}$ blood group was found to be the most common among the various blood groups in both males and females. Our study also shows a trend of longer BT in females and longer CT in females, but these were not statistically significant. Hence, we suggest more studies with larger sample size to confirm the results and to understand the reasons behind these variations.

\section{ACKNOWLEDGEMENT}

We are thankful to the staff of Department of Physiology, Jawaharlal Nehru Institute of Medical Sciences for their kind co-operation. We also thank Dr Akoijam B Singh of the Department of Community Medicine, Regional Institute of Medical Sciences, Imphal for his sincere effort during statistical analysis.

\section{REFERENCES}

[1] Roy B, Banerjee I, Sathian B, et al. Blood group distribution and its relationship with bleeding time and clotting time: a medical school based observational study among Nepali, Indian and Sri Lankan students. Nepal J Epidemiol 2011;1(4):135-40.

[2] Kaur M, Singh A, Bassi R, et al. Blood group distribution and its relationship with bleeding and clotting time. Natl J Pharm Pharmacol Physiol 2015;5(3):253-7.

[3] Daniel M, Jberoo MC, Stead RE, et al. Is admission for epistaxis more common in Caucasian than in Asian people? Preliminary study. Clin Otolaryngol 2006;31:386-389.

[4] Mahapatra B, Mishra N. Comparison of bleeding time and clotting time in different blood groups. Am J Infect Dis 2009;5(2):106-8.

[5] Baishya R, Sarkar R, Barman B. Blood group and its relationship with bleeding time and clotting time- an observational study among the 1st MBBS students of Gauhati Medical College, Guwahati. Int J Res Med Sci 2017;5(9):4147-50.

[6] Aleem A, Wahid M. Correlation of blood groups, bleeding time and clotting time in male and female students: an observational study. Pak J Pharm Res 2016;2(2):121-6.

[7] Adhana R, Chaurasiya R, Verma A. Comparison of bleeding time and clotting time between males and females. Natl Physiol Pharmacol 2018;8(10):1388-90.

[8] Miller VM, Jayachandran M, Hasimoto K, et al. Estrogen, inflammation and platelet phenotype. Gend Med 2008;(5 Suppl A):S91-A102.

[9] Milner PC, Martin JF. Shortened bleeding time in acute myocardial infarction and its relation to platelet mass. Brit Med J 1985;290(6484):1767-70. 